\section{National Kidney Month - March 2018}

Each year, March is designated National Kidney Month to raise awareness about the prevention and early detection of kidney disease. In the United States, kidney diseases are the ninth leading cause of death (1). Among U.S. adults aged $\geq 20$ years, $15 \%$ (30 million persons) are estimated to have chronic kidney disease. Chronic kidney disease is defined as damaged kidneys or a glomerular filtration rate (i.e., a measure of kidney function) $<60 \mathrm{~mL} / \mathrm{min} / 1.73 \mathrm{~m}^{2}$ for $>3$ months $(2,3)$. Chronic kidney disease is also estimated to be more common in women than in men (2,3). However, among persons with moderate to severe chronic kidney disease, awareness of having the disease was lower in women than in men (3). Risk factors for chronic kidney disease include diabetes, high blood pressure, cardiovascular disease, and obesity (2); controlling diabetes and high blood pressure can delay or prevent chronic kidney disease and improve health outcomes (2). CDC supports the Chronic Kidney Disease Surveillance System (https://www.cdc.gov/ckd/surveillance) to document and monitor kidney disease and its risk factors in the U.S. population and to track progress in kidney disease prevention, detection, and management. This week's $M M W R$ issue includes a report on acute kidney injury, a risk factor for developing or worsening chronic kidney disease. Information is available about kidney disease prevention and control at https://www.nkdep.nih.gov/ and about diabetes prevention and control at https://www.cdc.gov/diabetes.

\section{References}

1. Kochanek KD, Murphy SL, Xu JQ, Arias E. Mortality in the United States, 2016. NCHS data brief, no 293. Hyattsville, MD: National Center for Health Statistics; 2017. https://www.cdc.gov/nchs/ products/databriefs/db293.htm

2. CDC. National chronic kidney disease fact sheet, 2017. Atlanta, GA: US Department of Health and Human Services, CDC; 2017. https://www.cdc.gov/kidneydisease/pdf/kidney_factsheet.pdf

3. CDC. Chronic kidney disease surveillance system-United States. Atlanta, GA: US Department of Health and Human Services, CDC; 2017. https://nccd.cdc.gov/CKD/default.aspx

\section{Trends in Hospitalizations for Acute Kidney Injury — United States, 2000-2014}

\author{
Meda E. Pavkov, MD, $\mathrm{PhD}^{1}$; Jessica L. Harding, $\mathrm{PhD}^{1}$; \\ Nilka R. Burrows, $\mathrm{MPH}^{1}$
}

Acute kidney injury is a sudden decrease in kidney function with or without kidney damage, occurring over a few hours or days. Diabetes, hypertension, and advanced age are primary risk factors for acute kidney injury. It is increasingly recognized as an in-hospital complication of sepsis, heart conditions, and surgery $(1,2)$. Its most severe stage requires treatment with dialysis. Acute kidney injury is also associated with higher likelihood of long-term care, incidence of chronic kidney disease and hospital mortality, and health care costs $(1,2)$. Although a number of U.S. studies have indicated an increasing incidence of dialysis-treated acute kidney injury since the late 1990s (3), no data are available on national trends in diabetes-related acute

\section{INSIDE}

294 Exposure to Electronic Cigarette Advertising Among Middle and High School Students — United States, 2014-2016

300 Vaccine-Derived Poliovirus Outbreaks and Events Three Provinces, Democratic Republic of the Congo, 2017

306 Emergence of Monkeypox - West and Central Africa, 1970-2017

311 Notes from the Field: False-Negative Hepatitis B Surface Antigen Test Results in a Hemodialysis Patient — Nebraska, 2017

313 Notes from the Field: Assessing Rabies Risk After a Mass Bat Exposure at a Research Facility in a National Park — Wyoming, 2017

315 QuickStats

Continuing Education examination available at https://www.cdc.gov/mmwr/cme/conted_info.html\#weekly.

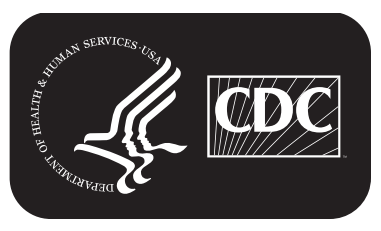

U.S. Department of Health and Human Services Centers for Disease Control and Prevention 